\title{
Auditory Sensory Gating in Hippocampus and Reticular Thalamic Neurons in Anesthetized Rats
}

\author{
Michael Krause, William E. Hoffmann, and Mihály Hajós
}

Background: Auditory gating is thought to reflect sensory information processing and is absent or diminished in schizophrenic patients. Although abnormal thalamic sensory processing has been proposed in schizophrenia, sensory gating of thalamic neurons has not been demonstrated experimentally. The aim of the present study was to establish whether auditory gating is present in the rat thalamus using a well-characterized animal model of auditory gating and schizophrenia.

Methods: Hippocampal electroencephalogram and single-unit activity in the thalamic reticular nucleus (nRT) were recorded in anaesthetized rats. Evoked potentials in the hippocampus and neuronal activity in the $n R T$ were monitored in response to bilateral auditory stimuli. The effects of the psychostimulant D-amphetamine and the antipsychotic haloperidol on auditory gating were evaluated.

Results: Thalamic reticular nucleus neurons showed gated responses to paired-tone auditory stimuli, resembling hippocampal auditory gating. D-amphetamine disrupted auditory gating of nRT neurons and abolished their burst activity. D-amphetamine also disrupted hippocampal auditory gating and induced hippocampal theta activity. The amphetamine-induced gating deficit was reversed by haloperidol in both regions.

Conclusions: Our findings provide the first experimental evidence for auditory gating of $n R T$ neurons. We demonstrated that amphetamine disrupts sensory processing of $n R T$ neurons, indicating similarities between hippocampal and thalamic sensory gating. These findings support the presumed connection between dopamine hyperfunction and abnormal thalamic filtering in schizophrenia. Biol Psychiatry 2003;53:244-253 (c) 2003 Society of Biological Psychiatry

Key Words: Schizophrenia, D-amphetamine, sensory gating model, haloperidol, electroencephalogram, single units

\footnotetext{
From the Pharmacia Corporation, Neurobiology, 301 Henrietta Street, Kalamazoo, Michigan.

Address reprint requests to Mihály Hajós, Pharm.D., Ph.D., Pharmacia Corporation, Neurobiology, 7251-219-419, 301 Henrietta Street, Kalamazoo MI 49007. Received March 12, 2002; revised May 20, 2002; accepted May 23, 2002.
}

\section{Introduction}

bnormal sensory processing is thought to be one of A the core pathologic mechanisms causal to schizophrenia (Braff 1999). Normal auditory processing in humans includes a reduced expression in the P50 response to the second of two consecutive stimuli, referred to as auditory gating. In contrast, impaired auditory gating may lead to sensory overload (McGhie and Chapman 1961; Venables 1964) and has been observed in schizophrenic patients (Adler et al 1998; Braff 1999; Cadenhead et al 2000; Clementz et al 1998; Croft et al 2001), in first-degree relatives of schizophrenic patients (Adler et al 1998; Clementz et al 1998), and in subjects with schizotypal personality disorder (Cadenhead et al 2000). The function of P50 auditory gating is still under debate; however, recent findings indicate an association between an auditory gating impairment and either positive symptoms or cognitive dysfunctions in schizophrenia (Cadenhead et al 2000). The fact that an improved clinical status correlates with a normalized sensory gating following clozapine treatment has further substantiated the connection between impaired sensory gating and schizophrenic symptoms (Nagamoto et al 1996).

To investigate the underlying neurobiology of auditory gating, various animal models showing auditory gating deficits have been developed. In the amphetamine model, sensory gating is disrupted by an elevated dopamine neurotransmission in animals (Adler et al 1986; BickfordWimer et al 1990; Stevens et al 1996) and humans (Light et al 1999).

Studies of auditory gating have focused mainly on the hippocampus, a region that is experimentally easily accessible in animals (Adler et al 1986, 1998; Stevens and Wear 1997). Auditory gating to paired tones can be demonstrated in rats using field potential recordings from the hippocampal CA3 region (Adler et al 1986; BickfordWimer et al 1990; Nagamoto et al 1996; Schridde and van Luijtelaar 2001; van Luijtelaar et al 2001). In the present study, however, we focused on another brain area, the thalamus, which is involved in sensory processing and may play a role in the pathophysiology of schizophrenia. In addition to its role in various sensory functions, the 
thalamus receives afferent input from the brain stem reticular activating system, from cortical and sub-cortical structures involved in emotion and memory (such as the amygdala and hippocampus), as well as from cortical association areas (Jones 1975). Hence, the thalamus plays an important role in filtering, gating, processing, and relaying information. In fact, a number of investigators have proposed that schizophrenia may involve abnormal thalamic filtering of sensory input to the cerebral cortex (Andreasen et al 1994, 1999; Braff 1999; Carlsson 2001). Morphometric analyses, as well as functional imaging studies, in patients suffering from schizophrenia consistently indicate a reduced volume of the thalamus and hippocampus (Andreasen et al 1994; Blennow et al 1996; Buchsbaum et al 1996; Ettinger et al 2001; Pakkenberg 1990).

The aim of the present study was to explore whether auditory gating processes are present in the rat thalamus, particularly the thalamic reticular nucleus (nRT), where several sensory modalities are represented (Guillery et al 1998). The unique anatomical connections of nRT neurons give rise to their presumed function in sensory processing (Crick 1984; Houser et al 1980; Jones 1975; McCormick and Bal 1994). This led us to study auditory gating mechanisms in this thalamic subregion using single-unit recordings in the auditory sector of the nRT (Shosaku and Sumitomo 1983). In addition, field potential recordings from the hippocampal CA3 region in anesthetized rats were studied. Auditory gating responses to various intertone stimulus intervals were studied both in $\mathrm{nRT}$ and hippocampus, and effects of enhanced dopamine neurotransmission on gating processes were investigated.

\section{Methods and Materials}

\section{Surgery}

Harlan male Sprague-Dawley rats (250-300 g) were anesthetized with chloral hydrate $(400 \mathrm{mg} / \mathrm{kg}$ intraperitoneally, supplemented by $150 \mathrm{mg} / \mathrm{kg}$ as necessary). The femoral vein and artery were cannulated with PE-50 tubing to administer drug and monitor blood pressure, respectively. Mean arterial blood pressure ranged between $60-90 \mathrm{~mm} \mathrm{Hg}$ in chloral hydrate-anesthetized rats. Body temperature was kept at $37^{\circ} \mathrm{C}$ by means of an isothermal heating pad (Braintree Scientific, Braintree, MA). Animals were placed in a Kopf stereotaxic unit with the incisor bar lowered by $3.3 \mathrm{~mm}$ below the interaural line corresponding to the atlas of Paxinos and Watson (1986).

\section{Electroencephalogram Recordings}

Following craniotomy, a monopolar, stainless steel macroelectrode (Rhodes Medical Instruments, Woodland Hills, CA) was lowered into the CA3 region of the left hippocampus, $3.8 \mathrm{~mm}$ ventral, $3.5 \mathrm{~mm}$ posterior, and $3.0 \mathrm{~mm}$ lateral from bregma
(Paxinos and Watson 1986). Hippocampal field potentials (electroencephalogram [EEG]) were recorded and amplified (Grass P15). Data were digitized and stored using the Spike2 software package (Cambridge Electronic Design, Cambridge, UK). The location of electrode track was verified in serial sections of frozen tissue. For quantitative EEG analysis, fast Fourier transformation was performed. Auditory evoked potentials were determined by measuring the potential difference between the positive and the negative deflection 20 and $40 \mathrm{msec}$ after stimulation (P20 and N40), respectively. For quantification, 25 sweeps were averaged, and the amplitude was determined and the ratio of the response after the second stimulus (test, T) and the first stimulus (conditioning, $\mathrm{C}$ ) was calculated. This T/C ratio is used as a measure of gating.

\section{Single-Unit Recordings}

Spontaneously active nRT neurons were monitored by means of extracellular recording techniques. Glass microelectrodes filled with $2 \mathrm{~mol} / \mathrm{L} \mathrm{NaCl}$ and $2 \%$ pontamine sky blue (impedance 2-4 $\mathrm{mol} / \mathrm{L} \mathrm{M} \Omega$ ) were lowered 5.2-5.6 mm into the left $\mathrm{nRT}(3.0 \mathrm{~mm}$ posterior and $3.6 \mathrm{~mm}$ lateral with respect to bregma), using a hydraulic microdrive (Kopf Instruments, Tujunga, CA). To identify neurons in the auditory sector of the reticular thalamus, continuous auditory stimulation was presented during electrode descent, and only those neurons that responded with activation to auditory stimuli were selected for our studies. Signals were amplified, low-pass filtered, and action potentials discriminated on-line (Neurolog System, Hertfordshire, UK). Data were digitized and stored using the Spike2 software package. At the end of each experiment, dye was deposited from the recording electrode using a $10 \mu \mathrm{A}$ DC current for 10-15 min. Location of the electrode tip was verified in serial sections of frozen tissue and subsequently determined by microscopic inspection of slidemounted and cresyl violet-stained sections. Data were analyzed by determining firing rates and interspike time interval histograms at baseline and after drug administration. To quantify changes in firing pattern, the ratio of the SD to the mean of peristimulus time histograms (PSTH) was calculated (coefficient of variance). Raster displays and PSTHs were constructed from the evoked responses to auditory stimulation on-line. The number of events (i.e., extracellularly recorded action potentials) before auditory stimulation and after the conditioning and test stimuli were determined using PSTHs. The number of events after the test stimulus divided by the number of events after the conditioning stimulus was called the T/C ratio. For statistical comparisons, the Student $t$ test was used. Differences were considered significant when $p \leq .05$.

\section{Stimulation}

Auditory stimulation consisted of two consecutive tone bursts of $10 \mathrm{msec}$ duration at a frequency of $5 \mathrm{KHz}$. The sound pressure level was $80-100 \mathrm{~dB}$ as determined with a sound level meter (RadioShack, Fort Worth, TX). Tones were delivered through hollow earbars. Tested intertone intervals (ITIs) in paired auditory stimuli were $0.5,1$, and $1.5 \mathrm{sec}$. The time interval between tone-pairs was $10 \mathrm{sec}$. 
A

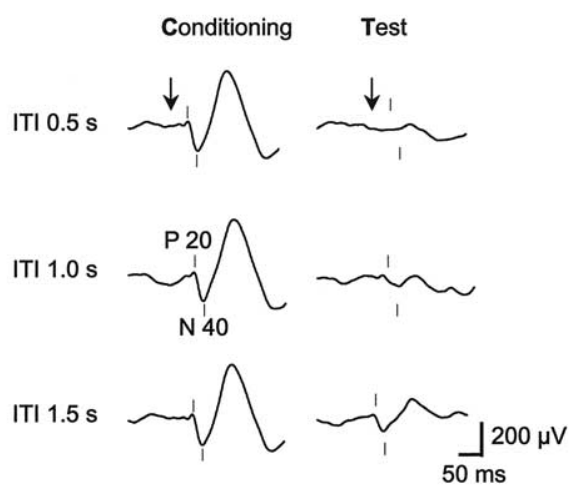

B

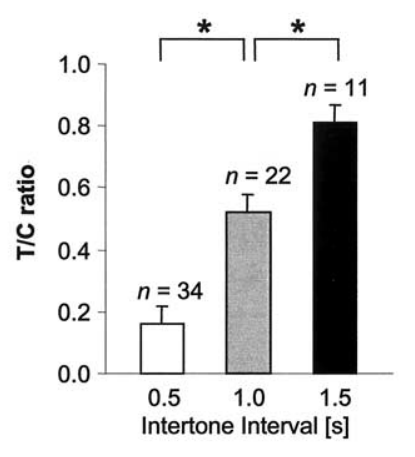

Figure 1. Auditory evoked potentials in the hippocampal electroencephalogram displayed gating. (A) Averaged auditory potentials evoked by conditioning and test stimulus. Amplitude between the P20 and the N40 response was determined (indicated by vertical lines), and the ratio of the test stimulus amplitude over conditioning stimulus amplitude was called T/C ratio. The amount of reduction in amplitude upon test stimuli depended on the intertone interval (ITI) and was maximal with an ITI of .5 sec. (B) Summary graph of averaged T/C values for $.5,1.0$, and $1.5 \mathrm{sec}$ ITI $(* p \leq .01)$.

\section{Drugs}

Drugs used in this study included D-amphetamine sulfate, dissolved in distilled water, and haloperidol dissolved in distilled water with equal molar amounts of citric acid (both Sigma, St. Louis, MO). Drugs were routinely administered intravenously. Injected volumes varied between 0.1 and $0.2 \mathrm{~mL}$.

\section{Results}

\section{Auditory Gating in the Hippocampus and Thalamic Reticular Nucleus}

HIPPOCAMPUS. Hippocampal field potential recordings revealed evoked potentials to auditory stimulation in anesthetized rats. The amplitude of the evoked auditory potential was determined by measuring the peak-to-peak amplitude between the P20 and the N40 waves of the evoked potentials (Figure 1A). Auditory gating, expressed as the ratio between evoked potentials to testing and conditioning stimuli (T/C), was evaluated at different ITIs.

In contrast to amplitudes of evoked potentials to conditioning stimuli, the amplitudes of evoked potential to test stimuli were dependent on the ITI (Figure 1A). With an ITI of $500 \mathrm{msec}$ the response to the test stimulus was greatly suppressed, indicated by a low T/C ratio of $0.16 \pm$ 0.03 ( $n=34$ animals). As ITIs were increased, an increase in the T/C ratio was established: for an ITI of $1000 \mathrm{msec}$ the T/C ratio was $0.52 \pm 0.06(n=22$ animals $)$ and with an ITI of $1500 \mathrm{msec}$ it was $0.8 \pm 0.06$ ( $n=11$ animals). Although it was found that the extent of auditory gating depended on the duration of ITI, paired-tone stimulations applied either at 0.5 - or 1 -sec intervals resulted in a significant auditory gating in the hippocampus $(p \leq .001$, Figure 1B).

RETICULAR THALAMIC NUCLEUS. Reticular thalamic neurons responded vigorously to auditory stimuli, with a typical discharge of bursts of action potentials lasting for up to $1 \mathrm{sec}$ ( $n=18$ neurons from 18 rats; Figure 2). Burst activity upon auditory stimulation was characterized by interspike interval histograms (Figure 2B). Auditory evoked activity of reticular thalamic neurons showed oscillations at $7-12 \mathrm{~Hz}$, with each burst comprising $\sim 6$ action potentials. During repeated stimulation (20 or more stimulus pairs at $0.1 \mathrm{~Hz}$ ), no habituation of the response was noticed. Because of the long-lasting activation of nRT neurons to auditory stimulation, gating of these neurons was tested by paired tones with 1-sec ITI. Activation of $\mathrm{nRT}$ neurons was more pronounced after the conditioning stimulus than after the test stimulus, as revealed by PSTHs, indicating auditory gating (Figure 2A). To quantify auditory gating, the number of spikes was determined in the $800 \mathrm{msec}$ poststimulus period following both conditioning and test stimuli. The average $\mathrm{T} / \mathrm{C}$ ratio, i.e., the number of spikes after test stimuli divided by the number of spikes after the conditioning stimuli, was 0.34 $\pm 0.04(n=18)$, demonstrating auditory gating in all tested neurons.

\section{Effects of D-amphetamine and Haloperidol on Auditory Gating and Theta Activity in the Hippocampus}

Systemic administration of D-amphetamine $(0.3-1 \mathrm{mg} / \mathrm{kg})$ disrupted auditory gating in the hippocampus CA3 region in anesthetized rats, as indicated by a significant increase of the T/C ratio to $0.57 \pm 0.11$ from the control $0.29 \pm$ 0.02 level ( $n=6$ animals, $p \leq .005$; Figure $3 \mathrm{~A}$ and $\mathrm{B})$. The increase in $\mathrm{T} / \mathrm{C}$ ratio was due to an increase and a decrease of the amplitude of evoked potentials in response to test and conditioning stimuli, respectively. Subsequent administration of haloperidol $(0.3 \mathrm{mg} / \mathrm{kg})$ significantly reversed the amphetamine-induced gating deficit (T/C ratio: $0.29 \pm 0.12 ; p \leq .01$ ) by antagonizing the action of amphetamine on the evoked potentials both to the test and conditioning stimuli (Figure 3C).

In addition to disrupting auditory gating, D-amphetamine induced a slow rhythmic activity, as revealed by simultaneous EEG recordings from the ipsilateral CA3 


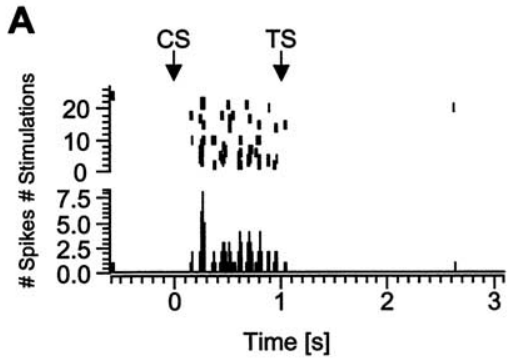

C

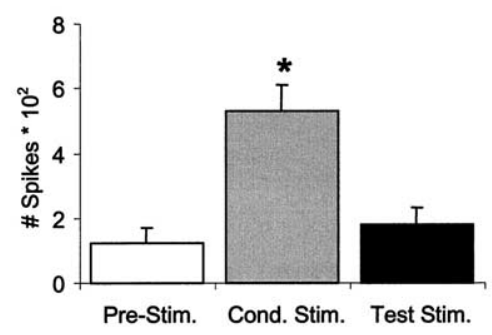

B

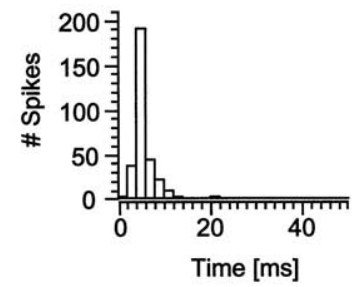

D

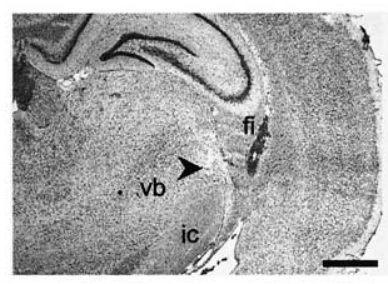

Figure 2. Single units in the reticular nucleus of the thalamus showed auditory gating. (A) Distribution of spikes over a period of 24 stimulations (upper panel) and poststimulus time histogram (lower panel, binsize: $2 \mathrm{msec}$ ) after conditioning (CS) and test stimulus (TS) of a single unit recorded in the reticular nucleus of the thalamus (nRT). Note that the single unit showed little spontaneous activity, and the majority of spikes occurred after the conditioning stimulus. (B) Interspike interval histogram of a single unit in nRT recorded for $250 \mathrm{msec}$ (binsize: $1 \mathrm{msec}$ ). The interspike interval is reminiscent of a bursting cell. Most spikes showed an interspike interval of $2.5 \mathrm{msec}$. (C) Bar diagram summarizing numbers of spikes in an 800-msec-window before the conditioning stimulus (Pre-Stim.), after the conditioning stimulus and after the test stimulus. Data are from single units recorded in nRT of 18 animals. The number of events after the conditioning stimulus is significantly higher than the number of events during the prestimulus period or after the test stimulus $(* p \leq .0005)$. (D) Horizontal section through the forebrain of a rat stained with cresyl violet. The arrowhead points to a lesion and a dye depository, indicating the position of the recording electrode in the ventral portion of the reticular nucleus of the thalamus. vb, ventrobasal complex of the thalamus; ic, internal capsule; fi, fimbria. Scale bar $=1 \mathrm{~mm}$.

region. Quantitative EEG analysis showed a significant increase in EEG power resulting in a peak frequency of 5.0 $\pm 0.2 \mathrm{~Hz}$, thereby indicating an increased synchrony in the theta frequency range (Figure $4 \mathrm{Ab}, \mathrm{Bb}$, and $\mathrm{Ca} ; n=6$ animals, $p \leq .05$ ). In addition to an increase of power in theta activity, D-amphetamine shifted the peak theta to a higher frequency (Figure $4 \mathrm{~b} ; p \leq .001$ ). Interestingly, haloperidol $(0.3 \mathrm{mg} / \mathrm{kg})$ failed to antagonize the synchronizing action of D-amphetamine on hippocampal EEG, in contrast to its reversing action of amphetamine-induced gating deficit. Thus, the D-amphetamine-induced increase in theta power of hippocampal EEG was not reversed by haloperidol, although the increase in theta frequency was slightly, but significantly, attenuated (Figure $4 \mathrm{~b} ; p \leq .05$ ).

\section{Effects of D-amphetamine and Haloperidol on Auditory Gating and Neuronal Activity in the Thalamic Reticular Nucleus}

Auditory gating of nRT neurons was significantly disrupted by D-amphetamine $(0.3-1 \mathrm{mg} / \mathrm{kg}, n=5)$. Damphetamine reduced the number of spike discharges after conditioning stimuli and increased the number of spike discharges after the test stimuli (Figure 5A; Figure $6 \mathrm{Ab}$ and $\mathrm{Bb}$ ). The average $\mathrm{T} / \mathrm{C}$ ratio was $0.27 \pm 0.06$ under control conditions and increased significantly after administration of D-amphetamine to $0.85 \pm 0.11(p \leq .01$, Figure 6Aa). At the same time, nRT neurons changed their firing mode from burst firing to single-spike firing (Figure $5 \mathrm{Ba}$ and $\mathrm{Bb}$ ). Accordingly, the coefficient of variation (CV) of interspike timing changed significantly from 1.14 \pm 0.17 under control conditions to $1.50 \pm 0.10(p \leq .01$, Figure $6 \mathrm{Ba}$ ) after administration of D-amphetamine, reflecting a less regular firing pattern. D-amphetamineinduced changes in both gating characteristics and firing mode were reversed by administration of haloperidol $(0.3$ $\mathrm{mg} / \mathrm{kg} ; n=5, p \leq .05$; Figure $5 \mathrm{Ca}$ and $\mathrm{Cb}$ and Figure 6 ), indicated by a reduction in T/C ratio $(p \leq .05)$ and $\mathrm{CV}(p$ $\leq .05$ ), respectively (Figure 6A and B).

\section{Discussion}

The present results provide the first electrophysiological evidence for the presence of auditory gating in nRT. The 
A

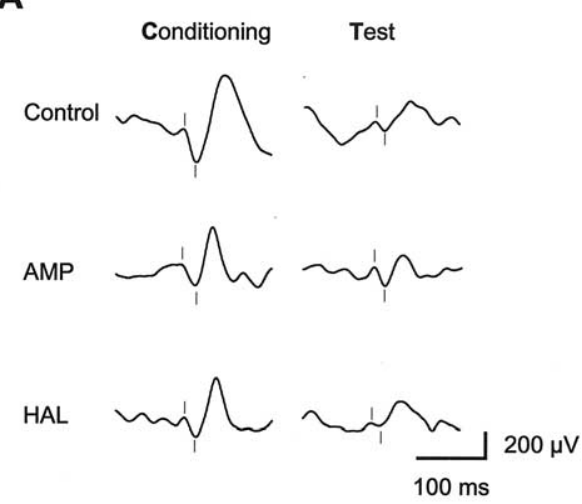

C

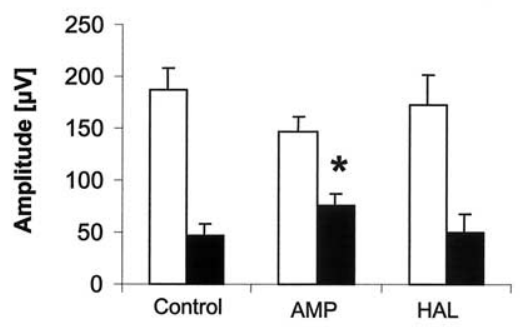

B

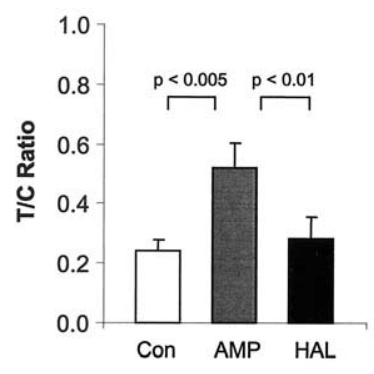

Figure 3. Effects of D-amphetamine and haloperidol on auditory gating and amplitudes of auditory evoked potentials in the hippocampal electroencephalogram. (A) Averaged auditory evoked potentials after conditioning and test stimulus (intertone interval .5 sec) in control conditions, after administration of D-amphetamine (AMP, $1.0 \mathrm{mg} / \mathrm{kg}$ ) and after additional administration of haloperidol (HAL, $.3 \mathrm{mg} / \mathrm{kg}$ ). (B) Summary graph showing a significant increase in T/C ratio after AMP, which was restored by HAL ( $n=6$ animals). (C) Damphetamine $(.3$ or $1.0 \mathrm{mg} / \mathrm{kg})$ caused a decrease in the amplitude of the conditioning response (empty bars) and an increase in the amplitude of the test response (black bars). Haloperidol $(.3 \mathrm{mg} / \mathrm{kg})$ reversed these effects $(n$ $=6$ animals, ${ }^{*} p \leq .05$ vs. control). psychoactive drug D-amphetamine disrupted auditory gating of nRT neurons and abolished their burst activity concomitantly with impairing hippocampal auditory gating. In $\mathrm{nRT}$, both the D-amphetamine-induced disruption of auditory gating and the burst activity were reversed by haloperidol. Haloperidol also restored auditory gating in the hippocampus but failed to antagonize the D-amphetamine-induced increase in theta activity. These electrophysiological data support a role of nRT neurons in sensory processing in an animal model, corroborating the D-amphetamine-induced auditory gating deficit model.

\section{Similar Auditory Gating in the Hippocampus and Thalamic Reticular Nucleus}

The design of the present study enabled us to investigate and confirm auditory gating in the hippocampal CA3 region by utilizing a well-defined animal model for schizophrenia (Adler et al 1986; Miller et al 1992; Stevens et al 1996). The same model was used to study auditory gating in the nRT, a brain region where auditory gating is still unexplored. As shown in humans and animals, auditory stimulation elicited hippocampal evoked potentials and displayed gating when paired tones were delivered with an intertone interval (ITI) shorter than $1.5 \mathrm{sec}$. The degree of gating depended on the duration of the ITI, and consistent with previous findings the response to the second (test) tone was significantly suppressed with an ITI of 0.5 or $1 \mathrm{sec}$.

In a similar experiment, single units in the auditory sector of the nRT responded to pairs of auditory stimuli with several bursts of action potentials. The evoked burst activity of nRT neurons showed a characteristic oscillatory response and lasted up to $1 \mathrm{sec}$, as reported previously (Cotillon et al 2000; Shosaku and Sumitomo 1983). Because of this long-lasting response, gating of these neurons was tested by paired tones with an ITI of $1 \mathrm{sec}$, which induced a gated auditory response in the hippocampus as well (see above). Firing activity of NRT neurons was much more pronounced after the conditioning stimulus than after the test stimulus when stimuli were presented 1 sec apart from each other. This finding is interpreted as gating and may indicate an important role of the $\mathrm{nRT}$ in filtering and processing of auditory signals.

\section{Mechanisms Underlying Auditory Gating: Lemniscal versus Nonlemniscal Auditory Pathways}

It has been proposed that signal processing in the auditory system upstream of the cochlear nucleus can be broadly divided into the lemniscal pathway and the nonlemniscal pathway. The lemniscal pathway includes areas or nuclei such as the brain stem reticular formation and the medial septal nucleus. The nonlemniscal pathway, which corresponds to the central auditory pathway, includes inter alia the medial geniculate body of the thalamus and the auditory cortex (Simpson and Knight 1993). Interestingly, functional studies revealed that auditory gating is primarily observed in regions of the lemniscal pathway, such as the brain stem reticular formation (Moxon et al 1999) and the medial septum (Miller and Freedman 1993). In the hippocampus, both lemniscal and nonlemniscal auditory 
Aa

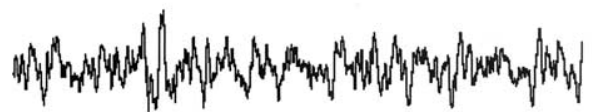

Ab

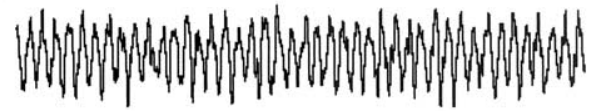

Ac

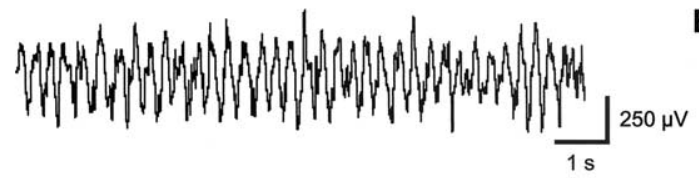

$\mathrm{Ba}$

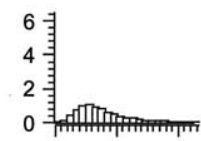

Bb

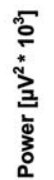

Bc

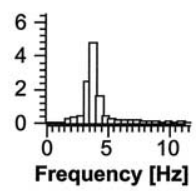

Ca

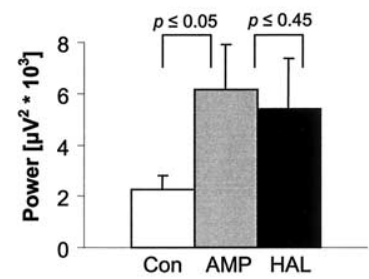

$\mathrm{Cb}$

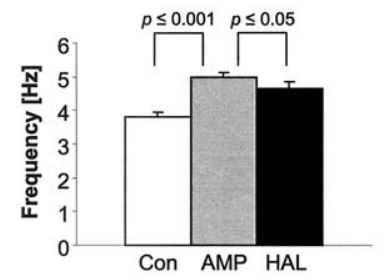

Figure 4. Effects of D-amphetamine and haloperidol on slow rhythmic activity in the hippocampal electroencephalogram (EEG). Hippocampal EEG (A) and power spectra (B) under control conditions (a), after administration of D-amphetamine (b, .3 or $1.0 \mathrm{mg} / \mathrm{kg}$ ), and after subsequent administration of haloperidol (c, .3 $\mathrm{mg} / \mathrm{kg}$ ). D-amphetamine induced a slow rhythmic activity in the hippocampal EEG in the theta frequency range, indicated by an increase in power between 3 and $6 \mathrm{~Hz}$. The power of the rhythmic activity remained unchanged after administration of haloperidol. (C) Summary graph showing the results of changes in power (a) and frequency (b) from the EEG recordings of 6 animals. pathways converge, resulting in a gated response to auditory stimuli in the CA3 region (Adler et al 1998). A modulatory action on hippocampal activity by the brain stem has been demonstrated (Vertes and Kocsis 1997) and is thought to contribute to auditory gating in this brain region (Bickford et al 1993; Vertes and Kocsis 1997). But how do these auditory pathways relate to the nRT and how do they contribute to auditory gating in this thalamic region? Auditory gating has not been observed in the medial geniculate nucleus (Bickford-Wimer et al 1990; Shosaku et al 1989; Yingling and Skinner 1976) or in the auditory cortex (Moxon et al 1999). Thus, an involvement of these two main excitatory inputs to the nRT can be ruled out in the generation of a gated auditory response. Responses of single units to paired auditory stimuli in the nRT share some characteristics with single units in the brain stem reticular formation. In both areas the response to the second tone is largely suppressed, demonstrating a powerful sensory gating, although firing latencies to auditory stimuli differ tremendously (Bickford-Wimer et al 1990; Cotillon et al 2000; Moxon et al 1999). Hence, it is conceivable that a diminished response to the second tone in nRT (i.e., auditory gating) may be related to an afferent input from the brain stem reticular formation. Some anatomical and electrophysiological findings support this hypothesis. Cholinergic afferents from the pons to the nRT have been confirmed using immunocytochemical methods (Pare et al 1988; Sofroniew et al 1985), and indeed the action of acetylcholine on neurons in the nRT leads to burst firing (Dingledine and Kelly 1977; McCormick and
Prince 1986). This hypothesis is tempting, because it postulates a common mechanism for auditory gating in nRT and hippocampus.

\section{Effects of D-amphetamine on Auditory Gating and EEG in Hippocampus}

Recent neuroimaging findings in schizophrenic patients provide evidence for a dopamine hyperfunction in this disease (Abi-Dargham et al 2000; Breier et al 1997; Laruelle and Abi-Dargham 1999; Laruelle et al 1996) and validate the choice for the D-amphetamine model of schizophrenia (Snyder 1973). Enhanced dopaminergic neurotransmission by pharmacological manipulation leads to impaired auditory gating in animals (Adler et al 1986; Bickford-Wimer et al 1990; Stevens et al 1996) and humans (Light et al 1999). In line with these observations, the present findings demonstrate that systemic administration of D-amphetamine disrupted auditory gating both in the hippocampus and nRT in anesthetized rats. Our results therefore not only support but also extend the D-amphetamine model of schizophrenia.

The present results confirm that systemic administration of D-amphetamine disrupts auditory gating by decreasing the conditioning amplitude and increasing the test amplitude of evoked responses to auditory stimuli (BickfordWimer et al 1990). The dopamine D2 receptor antagonist haloperidol reversed the D-amphetamine-induced gating deficit. Additionally, D-amphetamine induced a slow rhythmic activity in the hippocampal EEG, with a significant increase in theta power and frequency, as revealed by 
Aa

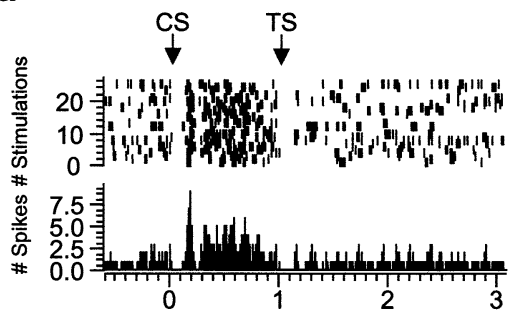

Ba

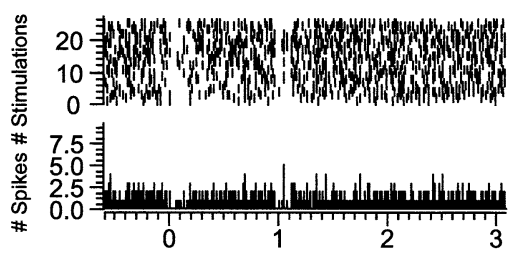

$\mathrm{Ca}$

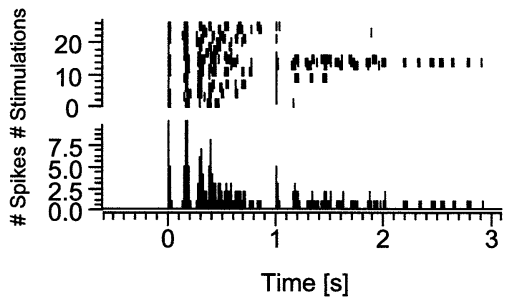

$\mathbf{A b}$

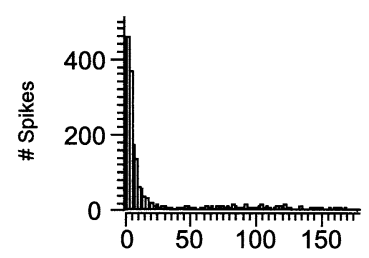

Bb

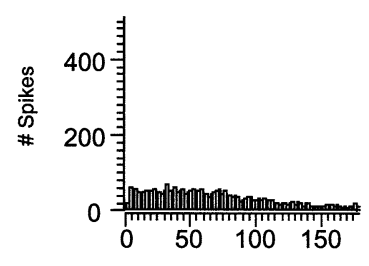

$\mathrm{Cb}$

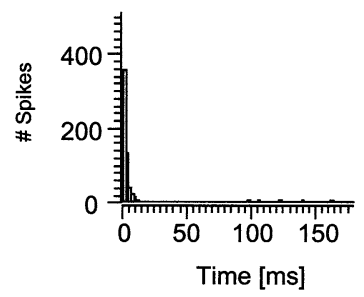

Figure 5. Effects of D-amphetamine and haloperidol on auditory evoked spike discharge of a representative single unit recorded in the reticular nucleus of the thalamus. (Aa) In control conditions the unit responded with a higher number of spikes after the conditioning stimulus (CS) than after the test stimulus (TS). The unit fired preferentially in bursts as indicated by the interspike interval histogram (Ab). (Ba) Administration of D-amphetamine (AMP, $.3 \mathrm{mg}$ / $\mathrm{kg}$ ) reduced the number of spikes after the conditioning stimulus and increased the number of spikes after the test stimulus. At the same time, burst firing was abolished and singlespike firing was prevailing (Bb). (C) Haloperidol (HAL, .3 mg/kg) reversed the effects of AMP. Accordingly, the unit responded with a higher discharge after the CS and fired in bursts (Cb). quantitative EEG analysis. In contrast to its reversing action on the gating deficit, haloperidol failed to antagonize the synchronizing action of D-amphetamine on hippocampal EEG, suggesting that D-amphetamine-induced theta activity is not primarily related to an enhanced dopaminergic neurotransmission. D-amphetamine also induces noradrenaline release in the hippocampus (Kuczenski et al 1995; Light et al 1999), and an alteration in noradrenergic neurotransmission affects hippocampal EEG activity. Inhibition of ascending noradrenergic neurons in the locus coeruleus attenuates hippocampal theta activity (Berridge and Foote 1991; Kuczenski et al 1995; Light et al 1999). Along these lines, we have recently shown that reboxetine, a selective noradrenaline reuptake inhibitor, enhances theta oscillations of septal neurons and increases hippocampal theta activity by increasing extracellular noradrenaline levels (Hajós et al 2001). Interestingly, theta peak frequency but not theta power is dependent on the activation of dopamine receptors. Thus, theta peak frequency is increased by the dopamine receptor agonist apomorphine, whereas it is shifted to lower frequencies by the dopamine receptor antagonist haloperidol (Yamamoto 1988). In line with these findings, our results show a slight shift of D-amphetamine-induced theta peak frequency to a lower level. Taken together, it is concluded that D-amphetamine disrupts auditory gating in the hippocampus and induces theta activity predominantly via enhancing dopaminergic and noradrenergic neurotransmission, respectively. In addition, no correlation was found between hippocampal theta activity and the degree of auditory gating under physiologic conditions (Schridde and van Luijtelaar 2001).

\section{Effects of D-amphetamine on Auditory Gating in the Reticular Thalamic Nucleus}

Systemic administration of D-amphetamine modified neuronal activity of the $\mathrm{nRT}$ to a great extent, which may have an impact on information processing. Firstly, D-amphetamine disrupted the auditory gating, similar to an impaired auditory gating as described in the hippocampus. The disrupted auditory gating of nRT neurons could have a profound effect on thalamic auditory information processing, owing to the reciprocal connection between nRT and medial geniculate neurons. Secondly, D-amphetamine increased spontaneous activity of nRT neurons and shifted 
$\mathrm{Aa}$

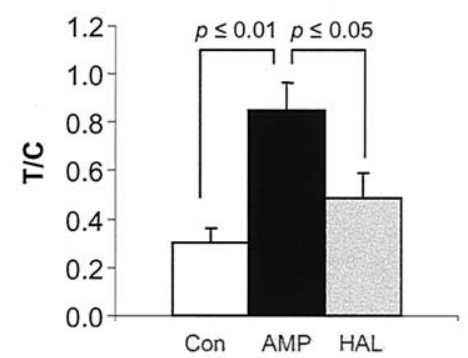

$\mathrm{Ba}$

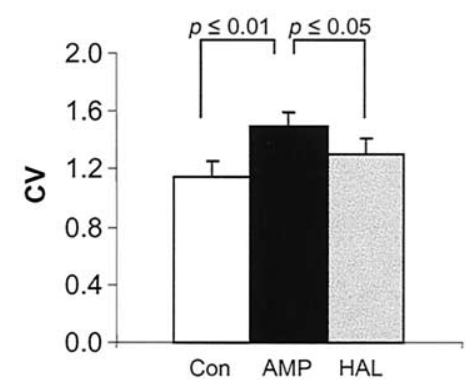

Ab

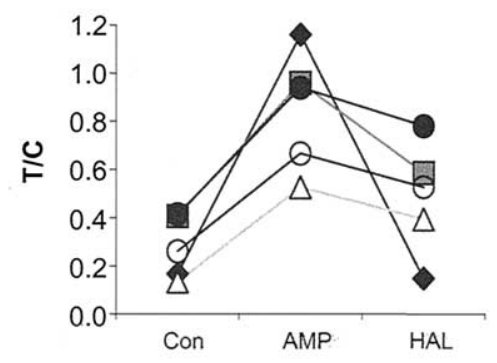

$\mathrm{Bb}$

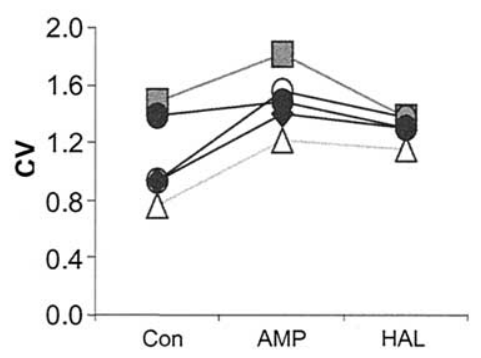

Figure 6. Summary graphs for auditory gating in single units in the reticular thalamic nucleus. (A) Number of spikes after test stimulus divided by number of spikes after conditioning stimulus ( $\mathrm{T} / \mathrm{C}$ ratio). Averaged T/C ratios after administration of D-amphetamine (AMP, .3 or $1.0 \mathrm{mg} / \mathrm{kg}$ ) were significantly different from control conditions (Con). Haloperidol (HAL, .3 $\mathrm{mg} / \mathrm{kg}$ ) reversed this effect. (B) Coefficient of variance $(\mathrm{CV})$ of interspike intervals in control conditions (Con), after administration of AMP (.3 or $1.0 \mathrm{mg} / \mathrm{kg})$, and after administration of HAL $(.3 \mathrm{mg} / \mathrm{kg})$. Coefficient of variance after AMP was significantly different $(* p \leq .05)$ from $\mathrm{CV}$ in control conditions or after administration of HAL. (a) bar diagram; (b) single value diagram, $n=5$ animals. their burst firing to single-spike firing pattern, which could be linked to an increase in membrane potential as shown in vitro (Llinas and Jahnsen 1982). Alternatively, D-amphetamine may vastly enhance glutamatergic afferent inputs, thereby activating type I metabotropic glutamate receptors, which in turn leads to a membrane depolarization (Cox and Sherman 1999). Thirdly, D-amphetamine abolished the reverberating discharge of spike bursts with a frequency of 7-10 Hz that followed upon auditory stimulation (Cotillon and Edeline 2000; Cotillon et al 2000; Shosaku and Sumitomo 1983). These stimulus-evoked oscillations of bursts seem to be generated by an interaction between the auditory thalamus and the nRT without any involvement of the auditory cortex (Cotillon and Edeline 2000). Thus, it seems unlikely that changes at the level of the auditory cortex account for the observed amphetamine-induced changes in firing pattern seen in nRT neurons, but these regions may well be affected by changes in nRT. Finally, all D-amphetamine-induced changes in nRT neuronal activity were reversed by subsequent administration of haloperidol, suggesting the involvement of D2 receptors. Because expression of D2 receptors in the nRT is sparse (Ariano et al 1993; Goldsmith and Joyce 1994; Landwehrmeyer et al 1993; Okubo et al 1999), the action of D-amphetamine on nRT neurons could be indirect. Several cortical or subcortical afferents of the nRT, which are innervated by the dopaminergic system, such as the ventral pallidum, could account for this effect. Interestingly, injection of either dopamine or the D2 agonist quinpirole into the nucleus accumbens leads to impairment in hippocampal and cortical sensory motor gating (de Bruin et al 2001; Swerdlow et al 1990), and a projection from the ventral pallidum to the nRT has been documented in a number of anatomical studies (Groenewegen et al 1993; Haber et al 1985; Hazrati and Parent 1991; Nauta 1979). In fact, repeated stimulation of the ventral pallidum leads to single-spike firing in nRT neurons (Lavin and Grace 1994; Pinault and Deschenes 1992), suggesting that this pathway could convey changes in dopaminergic neurotransmission to the nRT.

In summary, we propose a sensory gating function for the nRT based on the present results. D-amphetamine not only impaired hippocampal gating but altered neuronal activity and gating function in the nRT as well, indicating that sensory processing in both regions was affected. Thus, our results provide experimental support for abnormal thalamic filtering in schizophrenia as hypothesized by a number of investigators (Andreasen et al 1994, 1999; Blennow et al 1996; Braff 1999; Buchsbaum et al 1996; Carlsson 1988, 2001; Pakkenberg 1990). In addition, the D-amphetamine-induced auditory gating deficit model provides an opportunity to reveal details of the underlying neuropathology of impaired sensory gating in schizophrenia and therefore could suggest and validate a new pharmacotherapy for this disease. 
Parts of the results have been published previously in abstract form (Krause M, Hoffmann WE, Hajos M. Soc Neurosci Abstr 27, Program No. $663.13,2001)$.

\section{References}

Abi-Dargham A, Rodenhiser J, Printz D, Zea-Ponce Y, Gil R, Kegeles LS, et al (2000): From the cover: Increased baseline occupancy of D2 receptors by dopamine in schizophrenia. Proc Natl Acad Sci U S A 97:8104-8109.

Adler LE, Olincy A, Waldo M, Harris JG, Griffith J, Stevens K, et al (1998): Schizophrenia, sensory gating, and nicotinic receptors. Schizophr Bull 24:189-202.

Adler LE, Rose G, Freedman R (1986): Neurophysiological studies of sensory gating in rats: Effects of amphetamine, phencyclidine, and haloperidol. Biol Psychiatry 21:787-798.

Andreasen NC, Arndt S, Swayze V, Cizadlo T, Flaum M, O'Leary D, et al (1994): Thalamic abnormalities in schizophrenia visualized through magnetic resonance image averaging. Science 266:294-298.

Andreasen NC, Nopoulos P, O'Leary DS, Miller DD, Wassink T, Flaum M (1999): Defining the phenotype of schizophrenia: Cognitive dysmetria and its neural mechanisms. Biol Psychiatry 46:908-20.

Ariano MA, Fisher RS, Smyk-Randall E, Sibley DR, Levine MS (1993): D2 dopamine receptor distribution in the rodent CNS using anti-peptide antisera. Brain Res 609:71-80.

Berridge CW, Foote SL (1991): Effects of locus coeruleus activation on electroencephalographic activity in neocortex and hippocampus. J Neurosci 11:3135-3145.

Bickford PC, Luntz-Leybman V, Freedman R (1993): Auditory sensory gating in the rat hippocampus: Modulation by brainstem activity. Brain Res 607:33-38.

Bickford-Wimer PC, Nagamoto H, Johnson R, Adler LE, Egan M, Rose GM, et al (1990): Auditory sensory gating in hippocampal neurons: A model system in the rat. Biol Psychiatry 27:183-192.

Blennow K, Davidsson P, Gottfries CG, Ekman R, Heilig M (1996): Synaptic degeneration in thalamus in schizophrenia. Lancet 348:692-693.

Braff DL (1999): Psychophysiological and information-processing approaches to schizophrenia. In: Charney DS, Nestler EJ, Bunney BS, editors. Neurobiology of Mental Illness, 1st ed. New York: Oxford University Press, 258-271.

Breier A, Su TP, Saunders R, Carson RE, Kolachana BS, de Bartolomeis A, et al (1997): Schizophrenia is associated with elevated amphetamine-induced synaptic dopamine concentrations: Evidence from a novel positron emission tomography method. Proc Natl Acad Sci U S A 94:2569-2574.

Buchsbaum MS, Someya T, Teng CY, Abel L, Chin S, Najafi A, et al (1996): PET and MRI of the thalamus in nevermedicated patients with schizophrenia. Am J Psychiatry 153:191-199.

Cadenhead KS, Light GA, Geyer MA, Braff DL (2000): Sensory gating deficits assessed by the P50 event-related potential in subjects with schizotypal personality disorder. Am J Psychiatry 157:55-59.
Carlsson A (1988): The current status of the dopamine hypothesis of schizophrenia. Neuropsychopharmacology 1:179186.

Carlsson A (2001): A paradigm shift in brain research. Science 294:1021-1024.

Clementz BA, Geyer MA, Braff DL (1998): Poor P50 suppression among schizophrenia patients and their first-degree biological relatives. Am J Psychiatry 155:1691-1694.

Cotillon N, Edeline JM (2000): Tone-evoked oscillations in the rat auditory cortex result from interactions between the thalamus and reticular nucleus. Eur J Neurosci 12:36373650 .

Cotillon N, Nafati M, Edeline JM (2000): Characteristics of reliable tone-evoked oscillations in the rat thalamo-cortical auditory system. Hear Res 142:113-130.

Cox CL, Sherman SM (1999): Glutamate inhibits thalamic reticular neurons. J Neurosci 19:6694-6699.

Crick F (1984): Function of the thalamic reticular complex: The searchlight hypothesis. Proc Natl Acad Sci U S A 81:45864590.

Croft RJ, Lee A, Bertolot J, Gruzelier JH (2001): Associations of P50 suppression and desensitization with perceptual and cognitive features of "unreality" in schizotypy. Biol Psychiatry 50:441-446.

de Bruin NM, Ellenbroek BA, van Luijtelaar EL, Cools AR, Stevens KE (2001): Hippocampal and cortical sensory gating in rats: Effects of quinpirole microinjections in nucleus accumbens core and shell. Neuroscience 105:169-180.

Dingledine R, Kelly JS (1977): Brain stem stimulation and the acetylcholine-evoked inhibition of neurones in the feline nucleus reticularis thalami. J Physiol 271:135-54.

Ettinger U, Chitnis XA, Kumari V, Fannon DG, Sumich AL, O'Ceallaigh S, et al (2001): Magnetic resonance imaging of the thalamus in first-episode psychosis. Am J Psychiatry 158:116-118.

Goldsmith SK, Joyce JN (1994): Dopamine D2 receptor expression in hippocampus and parahippocampal cortex of rat, cat, and human in relation to tyrosine hydroxylase- immunoreactive fibers. Hippocampus 4:354-373.

Groenewegen HJ, Berendse HW, Haber SN (1993): Organization of the output of the ventral striatopallidal system in the rat: Ventral pallidal efferents. Neuroscience 57:113-142.

Guillery RW, Feig SL, Lozsadi DA (1998): Paying attention to the thalamic reticular nucleus. Trends Neurosci 21:28-32.

Haber SN, Groenewegen HJ, Grove EA, Nauta WJ (1985): Efferent connections of the ventral pallidum: Evidence of a dual striato pallidofugal pathway. J Comp Neurol 235:322335.

Hajós M, Hoffmann WE, Fitch CS, Merchant KM, Yu JMH, Robinson DD, et al (2001): Reboxetine induces theta oscillation of the septo-hippocampal system: A neurophysiological evidence for procognitive action. Soc Neurosci Abstr Progr No 975:15.

Hazrati LN, Parent A (1991): Projection from the external pallidum to the reticular thalamic nucleus in the squirrel monkey. Brain Res 550:142-146.

Houser CR, Vaughn JE, Barber RP, Roberts E (1980): GABA neurons are the major cell type of the nucleus reticularis thalami. Brain Res 200:341-354. 
Jones EG (1975): Some aspects of the organization of the thalamic reticular complex. J Comp Neurol 162:285-308.

Kuczenski R, Segal DS, Cho AK, Melega W (1995): Hippocampus norepinephrine, caudate dopamine and serotonin, and behavioral responses to the stereoisomers of amphetamine and methamphetamine. J Neurosci 15:1308-1317.

Landwehrmeyer B, Mengod G, Palacios JM (1993): Differential visualization of dopamine D2 and D3 receptor sites in rat brain. A comparative study using in situ hybridization histochemistry and ligand binding autoradiography. Eur J Neurosci 5:145-153.

Laruelle M, Abi-Dargham A (1999): Dopamine as the wind of the psychotic fire: New evidence from brain imaging studies. J Psychopharmacol 13:358-371.

Laruelle M, Abi-Dargham A, van Dyck CH, Gil R, D'Souza CD, Erdos J, et al (1996): Single photon emission computerized tomography imaging of amphetamine-induced dopamine release in drug-free schizophrenic subjects. Proc Natl Acad Sci U S A 93:9235-240.

Lavin A, Grace AA (1994): Modulation of dorsal thalamic cell activity by the ventral pallidum: Its role in the regulation of thalamocortical activity by the basal ganglia. Synapse 18:104-127.

Light GA, Malaspina D, Geyer MA, Luber BM, Coleman EA, Sackeim HA, et al (1999): Amphetamine disrupts P50 suppression in normal subjects. Biol Psychiatry 46:990-996.

Llinas R, Jahnsen H (1982): Electrophysiology of mammalian thalamic neurones in vitro. Nature 297:406-408.

McCormick DA, Bal T (1994): Sensory gating mechanisms of the thalamus. Curr Opin Neurobiol 4:550-556.

McCormick DA, Prince DA (1986): Acetylcholine induces burst firing in thalamic reticular neurones by activating a potassium conductance. Nature 319:402-405.

McGhie A, Chapman J (1961): Disorders of attention and perception in early schizophrenia. Br J Med Psychol 34:103115.

Miller CL, Bickford PC, Luntz-Leybman V, Adler LE, Gerhardt GA, Freedman R (1992): Phencyclidine and auditory sensory gating in the hippocampus of the rat. Neuropharmacology 31:1041-1048.

Miller CL, Freedman R (1993): Medial septal neuron activity in relation to an auditory sensory gating paradigm. Neuroscience 55:373-380.

Moxon KA, Gerhardt GA, Bickford PC, Austin K, Rose GM, Woodward DJ, et al (1999): Multiple single units and population responses during inhibitory gating of hippocampal auditory response in freely-moving rats. Brain Res 825:7585.

Nagamoto HT, Adler LE, Hea RA, Griffith JM, McRae KA, Freedman R (1996): Gating of auditory P50 in schizophrenics: Unique effects of clozapine. Biol Psychiatry 40:181-188.

Nauta HJ (1979): Projections of the pallidal complex: An autoradiographic study in the cat. Neuroscience 4:1853-1873.

Okubo Y, Olsson H, Ito H, Lofti M, Suhara T, Halldin C, et al (1999): PET mapping of extrastriatal D2-like dopamine receptors in the human brain using an anatomic standardization technique and [11C]FLB 457. Neuroimage 10:666-674.

Pakkenberg B (1990): Pronounced reduction of total neuron number in mediodorsal thalamic nucleus and nucleus accumbens in schizophrenics. Arch Gen Psychiatry 47:1023-1028.
Pare D, Smith Y, Parent A, Steriade M (1988): Projections of brainstem core cholinergic and non-cholinergic neurons of cat to intralaminar and reticular thalamic nuclei. Neuroscience 25:69-86.

Paxinos G, Watson C (1986): The Rat Brain in Stereotaxic Coordinates, 2nd ed. Sydney: Academic Press.

Pinault D, Deschenes M (1992): Muscarinic inhibition of reticular thalamic cells by basal forebrain neurones. Neuroreport 3:1101-1104.

Schridde U, van Luijtelaar G (2001): The role of hippocampal theta activity in sensory gating in the rat. Physiol Behav 74:257-266.

Shosaku A, Kayama Y, Sumitomo I, Sugitani M, Iwama K (1989): Analysis of recurrent inhibitory circuit in rat thalamus: Neurophysiology of the thalamic reticular nucleus. Prog Neurobiol 32:77-102.

Shosaku A, Sumitomo I (1983): Auditory neurons in the rat thalamic reticular nucleus. Exp Brain Res 49:432-442.

Simpson GV, Knight RT (1993): Multiple brain systems generating the rat auditory evoked potential. II. Dissociation of auditory cortex and non-lemniscal generator systems. Brain Res 602:251-263.

Snyder SH (1973): Amphetamine psychosis: A "model” schizophrenia mediated by catecholamines. Am J Psychiatry 130:61-67.

Sofroniew MV, Priestley JV, Consolazione A, Eckenstein F, Cuello AC (1985): Cholinergic projections from the midbrain and pons to the thalamus in the rat, identified by combined retrograde tracing and choline acetyltransferase immunohistochemistry. Brain Res 329:213-223.

Stevens KE, Luthman J, Lindqvist E, Johnson RG, Rose GM (1996): Effects of neonatal dopamine depletion on sensory inhibition in the rat. Pharmacol Biochem Behav 53:817-823.

Stevens KE, Wear KD (1997): Normalizing effects of nicotine and a novel nicotinic agonist on hippocampal auditory gating in two animal models. Pharmacol Biochem Behav 57:869874 .

Swerdlow NR, Braff DL, Masten VL, Geyer MA (1990): Schizophrenic-like sensorimotor gating abnormalities in rats following dopamine infusion into the nucleus accumbens. Psychopharmacology 101:414-420.

van Luijtelaar G, Fabene PF, de Bruin N, Jongema C, Ellenbroek BA, Veening JG (2001): Neural correlates of sensory gating in the rat: Decreased Fos induction in the lateral septum. Brain Res Bull 54:145-51.

Venables PH (1964): Input dysfunction in schizophrenia. In: Maher BA, editor. Orlando: Academic Press, 1-47.

Vertes RP, Kocsis B (1997): Brainstem-diencephalo-septohippocampal systems controlling the theta rhythm of the hippocampus. Neuroscience 81:893-926.

Yamamoto J (1988): Roles of cholinergic, dopaminergic, noradrenergic, serotonergic and GABAergic systems in changes of the EEG power spectra and behavioral states in rabbits. Jpn $J$ Pharmacol 47:123-134.

Yingling CD, Skinner JE (1976): Selective regulation of thalamic sensory relay nuclei by nucleus reticularis thalami. Electroencephalogr Clin Neurophysiol 41:476-482. 